\title{
Keep moving and stay in a good shape to find your homologous recombination partner
}

\author{
Hélène Bordelet ${ }^{1} \cdot$ Karine Dubrana $^{1}$ (i)
}

Received: 15 July 2018 / Revised: 31 July 2018 / Accepted: 2 August 2018 / Published online: 10 August 2018

(C) The Author(s) 2018

\begin{abstract}
Genomic DNA is constantly exposed to damage. Among the lesion in DNA, double-strand breaks (DSB), because they disrupt the two strands of the DNA double helix, are the more dangerous. DSB are repaired through two evolutionary conserved mechanisms: Non-Homologous End Joining (NHEJ) and Homologous Recombination (HR). Whereas NHEJ simply reseals the double helix with no or minimal processing, HR necessitates the formation of a 3'ssDNA through the processing of DSB ends by the resection machinery and relies on the recognition and pairing of this 3'ssDNA tails with an intact homologous sequence. Despite years of active research on HR, the manner by which the two homologous sequences find each other in the crowded nucleus, and how this modulates HR efficiency, only recently emerges. Here, we review recent advances in our understanding of the factors limiting the search of a homologous sequence during HR.
\end{abstract}

Keywords Homologous recombination $\cdot$ Homology search $\cdot$ DSB $\cdot$ Resection $\cdot$ Heterochromatin $\cdot$ Nuclear organization

\section{Introduction}

Genome stability implies that DNA damage, arising from either environmental stress or from endogenous events is robustly dealt with. Among DNA lesions, DNA double-strand breaks (DSB) are particularly deleterious. A single DSB can be lethal if unrepaired, particularly in a haploid organism such as yeast, and may lead to loss of genetic information and chromosome rearrangements if repaired improperly. Consequently, failure to repair DNA damages accurately leads to cancer and other diseases of ageing. From yeast to human, two conserved pathways for DSB repair are active: Non-Homologous End Joining (NHEJ) that simply religates DSB extremities, and Homologous Recombination (HR) that needs to copy an intact homologous sequence to reconstitute the broken site.

DNA DSBs are initially sensed and independently bound by the KU heterodimer and the MRX

Communicated by M. Kupiec.

Karine Dubrana

karine.dubrana@cea.fr

1 Laboratoire Instabilité et Organisation Nucléaire, iRCM, IBFJ, DRF, CEA. 2 INSERM, U967. 3 Université Paris Diderot et Paris Saclay, UMR967, Fontenay-aux-roses 92265, France complex (Mre11-Rad50-Xrs2; Mre11-Rad50-Nbs1, MRN in humans). This initial binding helps recruit the NHEJ ligase, Lig4 which ligates DSB extremities even in the absence of significant homology. If not ligated by NHEJ, DSB is processed to generate $3^{\prime}$ single strand overhangs by partially redundant nucleases, which include Mre11/Sae2, Dna2 and Exo1 (Mimitou and Symington 2008; Cejka 2015; Symington 2016). The resulting 3'ss overhangs generated by the concerted action of MRX/Sae2, Exo1 and Sgs1/Dna2 proteins are rapidly stabilized by RPA. RPA, in turn, recruits proteins of the $\operatorname{Rad} 52$ epistasis group, such as $\operatorname{Rad51}$, and these carry out strand invasion of the homologous template (Shinohara et al. 1992; Sung 1994; Baumann et al. 1996; Fortin and Symington 2002). New DNA synthesis copying the invaded duplex seals the DSB and after the resolution of the recombination intermediate structures, two intact DNA duplexes are restored (Symington et al. 2014; Wright et al. 2018).

HR can be separated into various sub-pathways that have different consequences for genome stability. HR is often considered to be an error-free mechanism for the repair of DSBs, as two-ended breaks are repaired primarily by Gene Conversion (GC) using a homologous duplex as template. However, if the donor sequence is not entirely homologous, $\mathrm{GC}$ can lead to loss of heterozygosity (LOH). Following HR repair, LOH is usually restrained to a small region surrounding the DSB 
but can be more extensive if HR occurs by Break Induced Replication (BIR). Indeed, during BIR repair the initial Displacement loop (D-loop) strand invasion event is followed by the establishment of a processive replication fork. This DNA synthesis can continue for hundreds of $\mathrm{kb}$ to the end of the chromosome, resulting in a long track of $\mathrm{LOH}$ (Llorente et al. 2008; Kramara et al. 2018). BIR is the repair of choice when only one DSB end is available for strand invasion, but is also thought to be at play to restart collapsed replication forks and to elongate telomeres that are lost in the absence of telomerase or when telomeres are uncapped (Lundblad and Blackburn 1993; McEachern and Haber 2006; Llorente et al. 2008).

In all cases, a prerequisite to HR repair is the encounter of the broken and homologous sequences. Although the sister chromatid, which shares perfect homology and is held in close proximity by the cohesin complex is the evident template for recombination, homologous sequences present on either the homologous chromosome (allelic recombination) or on a nonhomologous chromosome (ectopic recombination) can also be used. Then, two scenarios can be envisioned, one in which the homologous sequences are in proximity before DNA damage and a second in which the homologous sequence is actively searched by the broken molecule. Recent results indicate that the truth lies in between with a post damage pairing resulting from both diffusion and chance of encounters limited by pre-existing distance. As a consequence, the homology search process is largely impacted by chromatin mobility and chromosomes position in the nucleus. However, recent evidence indicates that mobility and distance between homologous loci are not the sole limiting factors for HR.

Here, we review recent advances in our understanding of the factors limiting the search of a homologous sequence during HR. We focus on the molecular steps that have been shown to limit the homology search process and present recent advances in our understanding of how the chromosomal context of the DSB, its nuclear localization and its chromatin status impact on the success of recombination processes.

\section{Finding a homologous sequence is a challenge in the nuclear context}

Over the last years, both microscopy and chromosome conformation capture experiments have revealed the non-random positioning of chromosomes in the nucleus. Although the patterns of this organization differ among eukaryotes, they impose constraints on the distances between sequences in the nucleus.

In haploid budding yeast, the tethering of the 16 centromeres at one pole and the gathering the 32 telomeres among 3-4 foci at the nuclear periphery imposes a Rabllike conformation during exponential growth (Taddei et al. 2010; Albert et al. 2012). This organization largely favours interaction between centromeric proximal sequences as well as contact between subtelomeres (Bystricky et al. 2005; Schober et al. 2008; Therizols et al. 2010; Duan et al. 2010; Agmon et al. 2013). Consistently, recombination between centromeres on one hand and between subtelomeric sequences on the other hand occurs efficiently (Burgess and Kleckner 1999; Brown et al. 2010; Agmon et al. 2013; Lee et al. 2016).

In mammals, chromosomes occupy distinct chromosome territories that intermingle only little with each other in accordance with scarce interchromosomal interactions which may disfavour ectopic recombination (Cremer and Cremer 2010; Rao et al. 2014). In most diploid organisms, with the exception of Dipterans, homologous chromosomes are apart in somatic cells (Cremer et al. 2001; Lorenz et al. 2003; Rong and Golic 2003; Joyce et al. 2016). Noteworthy, in human cells, homologous chromosomes are even more distant than what could be expected based on the known rules of chromosomes radial organization in the nucleus and probably less likely to recombine (Heride et al. 2010).

Thus, for both ectopic recombination and HR between homologs, finding the right donor sequence in the 3D space of the nucleus is the first challenging task in HR. Homology search has indeed early on been shown to be a ratelimiting step for recombination in budding yeast and proposed to occur through random 3D collisions rather than sliding along the DNA (Wilson et al. 1994). Although this study clearly gave us hints about the mechanism of homology search, because it used plasmids or linearized DNA for monitoring recombination, it might not reflect physiological recombination events. Indeed, these free DNA molecules have been shown to differ in their mobility from chromosomic sites (Gartenberg et al. 2004).

\section{Increasing mobility: a functional requirement for homology search?}

Chromosomic DNA motion is constrained in all organisms, not only by the polymeric nature of the chromatin fibre and by its confinement in the nucleus but also by the interaction of the chromosomes together and with nuclear structures, such as the nuclear membrane (Chubb et al. 2002; Zimmer and Fabre 2011; Hajjoul et al. 2013; Vasquez and Bloom 2014; Bronshtein et al. 2015; Marshall and Fung 2016).

In $S$. cerevisiae, the chromosomic DNA motion is limited by the tethering of centromeres and telomeres to nuclear membrane components (Hediger et al. 2002; Winey and Bloom 2012; Verdaasdonk et al. 2013; Strecker et al. 2016). This constraint is at least partially relieved in response to DNA damage. Indeed, the broken site mobility was shown to increase four- to fivefold and mobility of other sites in the genome also elevates, albeit to a lesser extent (Dion et al. 2012; Miné-Hattab and Rothstein 2012). Both global and 
local increase in motion depend on checkpoint activation and diverse, non-exclusive, mechanisms have been proposed (for a Review Smith and Rothstein 2017; Zimmer and Fabre 2018). First, a checkpoint-mediated disruption of centromeres anchoring has recently been proposed to participate in this $D S B$-induced chromatin mobility (Strecker et al. 2016). Second, a change in chromatin stiffness caused by both local and global chromatin remodelling may account for increased motion (Hauer et al. 2017). The increase of DSB ends mobility also depends on the recombination proteins $\operatorname{Rad} 51, \operatorname{Rad} 54$, and has thereby been proposed to promote recombination by allowing efficient scanning of the genome to find the appropriate template for repair (Dion et al. 2012; Miné-Hattab and Rothstein 2012). In agreement with this hypothesis, the targeting of the Ino80 chromatin remodelling factor that enhances locally chromatin mobility concomitantly increases spontaneous recombination between non-allelic homologous sequences (Neumann et al. 2012). However, this correlation could stem from Ino80mediated effects other than mobility increase. The fact that some mutants affected in DSB-induced mobility show no defect in HR efficiency further questions this functional relationship (Lee et al. 2016; Strecker et al. 2016).

Increased DSB mobility has also been observed in mammals but remains controversial (Dion and Gasser 2013; Lemaittre and Soutoglou 2015). On the one hand, several findings are similar to yeast where damaged chromatin displays a twofold increased mobility compared to unbroken DNA (Dimitrova et al. 2008; Krawczyk et al. 2012; Lottersberger et al. 2015). In this case, enhanced mobility requires 53BP1 and the INM proteins SUN1 and SUN2 (Dimitrova et al. 2008; Lottersberger et al. 2015). On the other hand, other studies have observed that chromatin containing DSBs exhibits limited mobility (Kruhlak et al. 2006; Soutoglou et al. 2007; Jakob et al. 2009). This apparent discrepancy may be attributed to the type of damage incurred and/or to the way it activates the ATM/ATR checkpoint, which was shown in yeast to contribute to DSB motion (Seeber et al. 2013). Consistently, ATM mediates DSB mobility and relocation of proximal DSBs to a repair centre in mammalian cells (Neumaier et al. 2012; Becker et al. 2014; Caron et al. 2015). A recent study in human cells revealed that the actin-nucleating Arp2-3 complex that promotes nuclear actin filament polymerisation is one of the driver of the motion of DSBs engaged in HR (Schrank et al. 2018). This sustains that in human cells as well, an active mechanism that promotes DSB movement participates in homology search. The same Arp2-3 complex is also the driver of heterochromatic DSB extrusion and perinuclear relocalisation in Drosophila (Caridi et al. 2018). Finally, the actin cytoskeleton seems to contribute to chromatin mobility in yeast but its requirement for DSB mobility remains to be tested (Spichal et al. 2016). Overall, the conservation of this mechanism in various species plead in favour of its functional relevance for DNA repair.

Although the modulation of chromosome mobility may enhance homology search efficiency, it is clearly not sufficient to overcome the constraints imposed by chromosome organization. Indeed, several studies in yeast recently showed that recombination efficiency decreases with the spatial distance between a DSB and its homologous targets (Burgess and Kleckner 1999; Agmon et al. 2013; Lee et al. 2016; Batté et al. 2017). Accordingly, sequences actively brought into close proximity either using the MAT Recombination Enhancer ( $\mathrm{Li}$ et al. 2012; Mehta et al. 2017) or clustering subtelomeric sequences (Batté et al. 2017) recombine more efficiently. Thus, the physical distance between the DSB and the recombination donor is a limiting factor for HR success. The fact that recombination efficiency and spatial distance anti-correlate also implies that there is a time limit for homology search.

\section{Resection, a ticking clock for homology search?}

The time limiting homology search may be imposed by the rate of resection. Despite the fact that some resection is required to unmask ssDNA that will search for a homologous sequence, extensive resection has also been shown to ultimately lead up to the loss of the DSB proximal sequences required for recombination.

DSB resection occurs through the concerted action of conserved redundant nucleases including the $\mathrm{MRX}^{\mathrm{MRN}}$ complex, Exo1 and the Dna2/Sgs $1^{\text {BLM/WRN }}$ complex. The MRX $^{\text {MRN_Sae }}{ }^{\text {CtIP }}$ complex first catalyses an endonucleolytic cleavage in the 5' strand that frees a $3^{\prime}$ extremity used as an entry point for the degradation of the DNA toward the DSB end by the $3^{\prime}-5^{\prime}$ exonuclease activity of Mre 11 (Cannavo and Cejka 2014). More extensive resection in the $5^{\prime}-3^{\prime}$ direction is taken over by the processive complexes Exo1 and Sgs1-Dna2 (for a review Symington and Gautier 2011). The 3'ssDNA formed is first coated by RPA and then by the Rad51 recombinase forming a filament that will engage the search for a homologous sequence. This search, if successful, will be followed by the strand invasion of the template sequence, DNA polymerization and resolution of the D-loop structure to restore intact duplex DNA (Symington et al. 2014; Wright et al. 2018).

At the biochemical level, the length of the homologous sequence coated by bacterial $\operatorname{Rad} 51$ ortholog RecA is a crucial factor in the rate-limiting step of homologous pairing in vitro (Forget and Kowalczykowski 2012). This possibly reflects a stabilisation of the duplex by the number of paired bases but could also result from the fact that the recombination filament is able to simultaneously bind multiple noncontiguous sequences. This has been observed in vitro for the RecA filament (Forget and Kowalczykowski 2012) and 
more recently in vivo in S. cerevisiae (Piazza et al. 2017). Although these observations explain that a certain amount of resected DNA is required for efficient homology search in vivo, the fact that slowing down resection can increase recombination efficiency at subtelomeric and some intrachromosomic DSBs (Lee et al. 2016; Batté et al. 2017) suggests that too much resection can also limit HR.

A possible rationale for these observations may be brought by the unstable nature of the 3'ssDNA overhang. Indeed, a study by the Diffley's laboratory showed that once formed by resection, the ssDNA is stable only few hours and later lost (Zierhut and Diffley 2008). Based on recent data, one can envision at least two mechanisms to account for the processing of the 3'ssDNA overhang. One is linked to the exhaustion of the RPA protein that can be caused by hyper-resection or uncontrolled replication and will expose unprotected ssDNA to the formation of secondary structures and enzymatic processing leading to its degradation (Chen et al. 2013; Toledo et al. 2013). Consistently, overexpressing subunits of the RPA complex increases the recombination efficiency (Lee et al. 2016). The second mechanism, which will depend on the local sequence context, is linked to the propensity of the ssDNA if bearing repeated elements to invade multiple sequences. These multi-invasions would form substrates for nucleases such as the 3'-flap Rad1-Rad10 nuclease leading to the processing and attrition of the 3'ssDNA overhang (for a review Lyndaker and Alani 2009). These competing strand invasions are particularly likely to occur at subtelomeres that harbour multiple repeated elements (X core, $Y^{\prime}$...) and could account for the rapid loss of telomere proximal sequences previously observed at subtelomeric DSBs (Batté et al. 2017). Parasitic recombination events probably also occur at intrachromosomic DSB flanked by multi-genes family or Ty elements (Jain et al. 2016). Therefore, the chromosomal environment and especially repeated elements can render DSB flanking sequences more or less prone to resection. This, together with the fact that the genetic information on the $3^{\prime}$ overhang is lost concomitantly with $5^{\prime}$ resection, explains how resection limits homology search and HR repair. It also provides a rationale to explain how increasing the size of the homology improves HR (Lee et al. 2016).

Excessive resection does not only limit homology search, but also affects repair outcomes. Indeed, in the context of a subtelomeric DSB, the telomeric proximal side of the break is very sensitive to resection and is rapidly lost preventing gene conversion, a mechanism that requires both DNA ends. The DSB can then only be repaired by break-induced replication (BIR), a pathway that requires only one DSB end but that induces long tracks of loss of heterozygosity (Batté et al. 2017). To avoid excessive ssDNA formation that would limit homology search and faithful recombination outcomes, the extent of resection needs to be kept under tight control.

\section{Resection is regulated at multiple levels}

An increasing amount of data indeed shows that resection is regulated at multiple level, ranging from direct modification of the nuclease enzymatic activities or the nuclease protein level to the modulation of their recruitment or efficiency by the chromatin context.

Resection is first regulated by checkpoint activation. At uncapped telomeres in yeast, phosphorylation of Exo1 by the checkpoint kinase Rad53 inhibits its nuclease activity and prevents accumulation of single-stranded DNA (Jia et al. 2004; Morin et al. 2008). In mammals, a negative regulation of Exo1 is also observed at double-strand breaks induced by IR or replication inhibitors. This negative feedback loop is triggered by the ATR-dependent phosphorylation of Exo1 that leads to its degradation and limits hyper-resection and genomic instability (Tomimatsu et al. 2017). The Sae $2^{\text {CtIP }}$ protein is also tightly regulated in several species both at the transcriptional and through post-translational modifications (for a review Andres and Williams 2017). Among post-translational modifications, phosphorylation by CDKs is critical to initiate resection in both human and S. Cerevisiae (Huertas et al. 2008; Huertas and Jackson 2009). In addition, Sae $2^{\text {CtIP }}$ can be acetylated in both budding yeast and human but with different consequences. CtIP acetylation by SIRT6 initiates HR, whereas Sae2 acetylation has been proposed to shunt it into autophagy-mediated degradation (Kaidi et al. 2010; Robert et al. 2011). More recently, the cytosolic form of a mitochondrial metabolic enzyme, the Fumarase, has been shown to be required to maintain Sae2 protein level, whereas this is linked to autophagy remains to be deciphered (Leshets et al. 2018).

A number of recent studies also showed that end resection is finely modulated not only at the level of nucleases and DNA processing enzymes activities, but also through the presence of functional or structural "barriers." Notably, in both yeast and mammals, the checkpoint protein $\operatorname{Rad} 9^{53 \mathrm{BP} 1}$ is constitutively bound to chromatin through the interaction between its Tudor domain and H3K79me (van Leeuwen et al. 2002; Huyen et al. 2004; Giannattasio et al. 2005; Wysocki et al. 2005; Grenon et al. 2007). This interaction is further strengthened around DSB sites through interaction of its BRCT domain with DSB-induced $\gamma \mathrm{H} 2 \mathrm{~A}$ (Javaheri et al. 2006; Hammet et al. 2007). This tight Rad9 ${ }^{53 \mathrm{BP} 1}$-Chromatin association has been proposed to act as a barrier to the resection activity of Sgs1-Dna2 possibly by reducing the association of Sgs1 to DSB ends (Lydall and Weinert 1995; Lazzaro et al. 2008; Ferrari et al. 2015; Bonetti et al. $2015) . \operatorname{Rad} 9^{53 \mathrm{BP} 1}$ is also recruited by $\mathrm{Dbp} 11^{\mathrm{TopBP} 1}$, forming a complex that restrains Dna2-mediated nucleolytic processing (Granata et al. 2010; Pfander and Diffley 2011; Villa et al. 2018). This seems conserved in human cells, where TOPBP1 stabilizes 53BP1 to the sites of damage to 
inhibit DSB resection (Cescutti et al. 2010; Zimmermann et al. 2013; Chapman et al. 2013; Ochs et al. 2016; Liu et al. 2017) and in S. pombe where the 53BP1 orthologue, Crb2, specifically inhibits the RecQ-helicase-dependent long-range resection pathway (Leland et al. 2018). In both S. pombe and mammalian cells, another resection inhibitor, Rev7 seems to be at play although its mechanism of action is unknown (Boersma et al. 2015; Xu et al. 2015; Leland et al. 2018). On the opposite, $\operatorname{Rad} 9^{53 \mathrm{BP} 1}$-mediated resection inhibition is counteracted by the Slx4-Rtt107 scaffold that compete for the interaction with Dbp11 and by the Fun30 $0^{\text {SMARCAD1 }}$ chromatin remodeler (Chen et al. 2012; Costelloe et al. 2012; Eapen et al. 2012; Dibitetto et al. 2016; reviewed in; Shimada and Gasser 2017).

Therefore, resection is both positively and negatively regulated by chromatin interacting factors to generate enough substrate for efficient search and pairing while avoiding excessive resection and 3'ssDNA loss that would limit homology search.

\section{Chromatin structure regulates HR}

Two main chromatin structures are usually distinguished, a lightly compacted and transcriptionally active euchromatin and a compacted and transcriptionally silent heterochromatin. However, recent genome wide analyses revealed a more complex pattern in most organisms, with non-expressed genes in euchromatin and various repressive chromatin structures defined by different histone modifications and histone binding proteins (Filion et al. 2010; Li and Reinberg 2011; van Steensel 2011; Politz et al. 2013; Becker et al. 2017). The examination of DSB repair taking into account these various chromatin environments has only recently been addressed by either genome wide studies mostly assessing euchromatic DSB sites (Aymard et al. 2014) or approaches specifically targeting particular heterochromatic sites (Goodarzi et al. 2008; Peng and Karpen 2009; Noon et al. 2010; Chiolo et al. 2011; Lemaître and Soutoglou 2014; Ryu et al. 2015; Janssen et al. 2016; Tsouroula et al. 2016; Batté et al. 2017).

These studies all show that the initial chromatin folding at the DSB sites, by itself, largely modulates HR. However, the molecular mechanisms at play still await further characterization. While we will discuss the occurrence and regulation of HR in the compact and transcriptionally silent heterochromatin in the next section, we would like to put emphasize on the fact that even euchromatic loci appear to differ in their capacity to perform HR depending on their chromatin structure. Indeed, HR has been shown to be the prevalent repair mechanism for endonuclease-induced DSB sites in transcriptionally active genes in both $S$. cerevisiae and human cell lines while non-coding or silent sequences exhibit a preference for NHEJ (Chaurasia et al. 2012; Aymard et al.
2014). Somehow counterintuitive when considering these data is the fact that the more compact and silent heterochromatin also mainly relies on HR in different organisms. This is notably the case for heterochromatic repeat-rich regions in G2 mouse cells (Beucher et al. 2009; Tsouroula et al. 2016) and in Drosophila pericentromeric heterochromatin (Chiolo et al. 2011).

\section{Euchromatin and heterochromatin have opposite effect on resection}

In human cells, the prevalence of HR in transcribed regions stems from the recruitment of the resection factor CtIP mediated by the binding of the LEDGF protein to the active chromatin marker histone $\mathrm{H} 3$ tri-methylated on lysine 36 (H3K36me3) (Daugaard et al. 2012). Functionally, enhanced CtIP recruitment, which is known to be critical to initiate resection, would favour the recruitment of Rad51 and the use of HR at active genes (Aymard et al. 2014). Another active histone mark, the acetylation of histone $\mathrm{H} 4$ lysine 16 also seems to promote resection and engagement in HR. Indeed, TSA treatment that increases $\mathrm{H} 4$ acetylation concomitantly favours the recruitment of the resection factor BReast CAncer 1 (BRCA1) and diminishes the association of the antiresection factor 53BP1 to FokI induced DSBs (Tang et al. 2013). Actively transcribed reporters that accumulate H4ac before DSB induction also recruit higher level of BRCA1 and lower 53BP1 (Tang et al. 2013). Both H3K36me3 and $\mathrm{H} 4 \mathrm{ac}$ seem thus to actively promote resection and engagement in HR.

While active transcription positively impacts on resection, heterochromatin has recently emerged as a negative regulator of this process in some organisms. Indeed, Sir-mediated heterochromatin at subtelomeric DSB has been shown to limit resection and to increase gene conversion efficiency by preventing loss of genetic information in S. cerevisiae (Batté et al. 2017). Resection is also regulated by heterochromatin to some extent in other eukaryotes, although the picture is less clear. Resection regulation seems to vary depending on the cell cycle phase and on the repressive chromatin type. On one end, lamina-associated heterochromatin limits DSB resection (Lemaître et al. 2014) as does pericentromeric heterochromatin in G1 cells (Tsouroula et al. 2016). On the other hand, resection seems to occur at normal rates at centromeres in both G1 and G2 cells (Tsouroula et al. 2016). However, resection occurs and seems even more rapid in Drosophila heterochromatin (Chiolo et al. 2011). It is to note that, in these studies, resection was mostly assessed by the visualization of ssDNA binding proteins' foci such as phosphorylated RPA or ATRIP that may alternatively reflect persistent binding. Notably, in Drosophila, the fastest appearance of ATRIP ${ }^{\text {ATR }}$, a protein recruited to resected DNA coated by RPA, could reflect an enhanced recruitment 
of ATRIP through direct interaction with HP1a which binding increases upon DSB induction of the DSB (Chiolo et al. 2011). Further studies directly evaluating ssDNA amount will be needed to fully understand the molecular events occurring and their consequences for repair.

\section{Limiting resection in heterochromatin: what functional consequences?}

In $S$. cerevisiae, limiting resection at silent subtelomeres clearly restrains resection-mediated loss of the telomeric proximal sequences and prevents mutagenic BIR repair (Batté et al. 2017). Sir-mediated chromatin structure could also participate to telomere capping and limit resection at the terminal TG repeats protecting telomere from unwanted recombination events (Lue and $\mathrm{Yu}$ 2017).

More generally, limiting resection in repeated heterochromatic regions should prevent repair through single strand annealing (SSA), thus limiting the loss of repeated sequences (Stark et al. 2004). This would be particularly relevant at centromeric-repeated sequences in mammalian cells which deletion can lead to centromere inactivation (Stimpson et al. 2010). However, both Drosophila and mammalian centromeric heterochromatin seem permissive to resection. Strikingly, in these cases, heterochromatin negatively regulates the assembly of the Rad51 recombination filament required for strand invasion. In both instances, resected DSBs have been shown to exit the heterochromatin domains
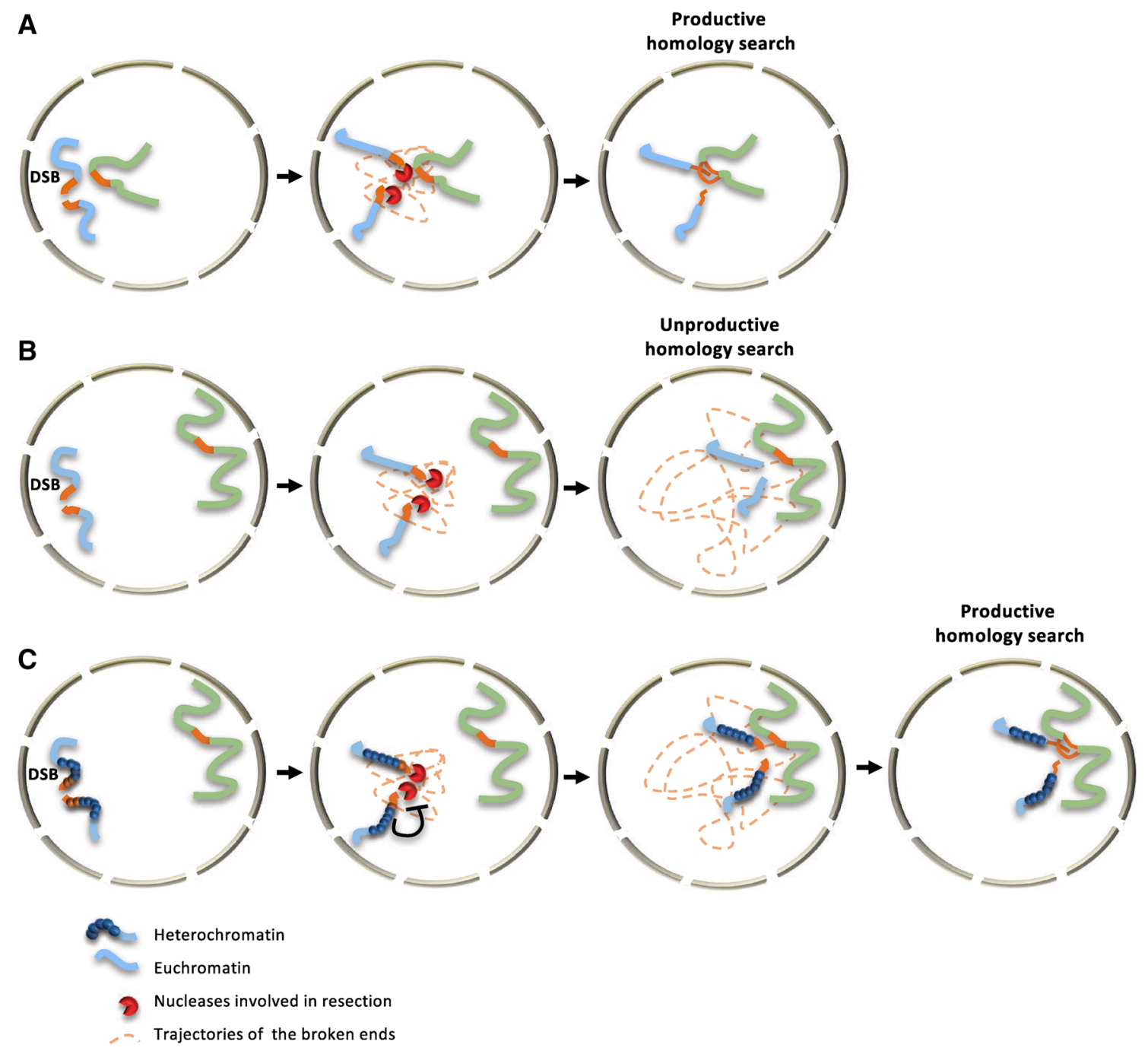

Fig. 1 A When a DSB occurs on a locus which is in close spatial proximity to the recombination donor, the two sites can encounter after resection has unmasked homologous sequences but prior elimination of the homologous sequence. The homology search process is then productive and recombination repair successful. B If the DSB and the recombination donor are too distant, resection will shrink
DSB flanking sequences eliminating homologous sequences prior encounter with the donor locus. DSB and global genome-induced mobility can eventually favour timely encounter. $\mathbf{C}$ The limitation of resection progression by a compact chromatin structure can provide the time for the moving DSB to find the homologous donor and allow a productive homology search 
prior Rad51 binding (Chiolo et al. 2011; Tsouroula et al. 2016). It is likely that the spatial separation between DNA end resection and homology search prevents illegitimate HR between repeats of different chromosomes that cluster in these domains.

\section{Conclusions}

The recent examination of DSB repair taking into account nuclear and chromatin organization, now allows an integrated picture of the steps limiting HR. Although the first limitation has long been known to be the search for a distant homologous matrix to copy (Barzel and Kupiec 2008), it now appears that the distance between the DSB and its repair template is not the sole limiting factor. Indeed, depending on the chromosomal context, resection may act as a countdown that limits the time for the break to explore the entire nucleus (Fig. 1). Soon after DSB occurrence, a race is engaged to cover the distance toward a homologous sequence prior the vanishing of its surrounding sequences. Along the way, unproductive invasions of homologous sequences followed by flap endonuclease processing or the resection machinery itself are ticking the clock. In that instance, both limiting resection and increasing the mobility of the genome may be successful tools to win the homology search race. Chromatin structure, more than being a simple obstacle to DNA repair now appears as a major regulator of HR. Heterochromatin acts at several levels ranging from resection regulation to the control of recombination filament assembly. Although this predicts that not all sequences will be equal in this race, how the mobility varies with chromatin structure and modulate HR efficiency remains to be deciphered.

These new concepts have been and will be key to improve genome-editing strategies. The notion that homology search is limited by the distance between the DSB site and the recombination donor was at the basis of the tethering of the donor DNA to Cas9 and more recently of the targeting of the donor to Cas 9 breaks by the Fkh1 protein from S. cerevisiae, two approaches that significantly increased genome-editing efficiency (Ma et al. 2017; Gu et al. 2017; Savic et al. 2017; Roy et al. 2018). In some cases, modulating mobility and/ or resection efficiency may also be key to successful Cas9 editing (Charpentier et al. 2018).

Acknowledgements We thank Stephane Marcand, Pascale Bertrand and Pablo Radicella for critical reading of the manuscript. Due to space limitations, we apologize to colleagues whose work is not cited here. This work was supported by grants from the Fondation pour la recherche médicale (DEP20131128535), and from the European Research Council under the European Community's Seventh Framework Program (FP7/2007 2013/European Research Council Grant Agreement 281287). HB was supported by a fellowship from the CEAIRTELIS PhD program.

\section{Compliance with ethical standards}

Conflict of interest The authors declare that they have no conflict of interest.

Open Access This article is distributed under the terms of the Creative Commons Attribution 4.0 International License (http://creativeco mmons.org/licenses/by/4.0/), which permits unrestricted use, distribution, and reproduction in any medium, provided you give appropriate credit to the original author(s) and the source, provide a link to the Creative Commons license, and indicate if changes were made.

\section{References}

Agmon N, Liefshitz B, Zimmer C, Fabre E, Kupiec M (2013) Effect of nuclear architecture on the efficiency of double-strand break repair. Nat Cell Biol 15:694-699. https://doi.org/10.1038/ncb27 45

Albert B, Léger-Silvestre I, Normand C, Gadal O (2012) Nuclear organization and chromatin dynamics in yeast: biophysical models or biologically driven interactions? Biochim Biophys Acta 1819:468-481. https://doi.org/10.1016/j.bbagrm.2011.12.010

Andres SN, Williams RS (2017) CtIP/Ctp1/Sae2, molecular form fit for function. DNA Repair 56:109-117. https://doi.org/10.1016/j. dnarep.2017.06.013

Aymard F, Bugler B, Schmidt CK, Guillou E, Caron P, Briois S, Iacovoni JS, Daburon V, Miller KM, Jackson SP, Legube G (2014) Transcriptionally active chromatin recruits homologous recombination at DNA double-strand breaks. Nat Struct Mol Biol 21:366-374. https://doi.org/10.1038/nsmb.2796

Barzel A, Kupiec M (2008) Finding a match: how do homologous sequences get together for recombination? Nat Rev Genet 9:2737. https://doi.org/10.1038/nrg2224

Batté A, Brocas C, Bordelet H, Hocher A, Ruault M, Adjiri A, Taddei A, Dubrana K (2017) Recombination at subtelomeres is regulated by physical distance, double-strand break resection and chromatin status. EMBO J 36:2609-2625. https://doi.org/10.15252 /embj.201796631

Baumann P, Benson FE, West SC (1996) Human Rad51 protein promotes ATP-dependent homologous pairing and strand transfer reactions in vitro. Cell 87:757-766

Becker A, Durante M, Taucher-Scholz G, Jakob B (2014) ATM alters the otherwise robust chromatin mobility at sites of DNA doublestrand breaks (DSBs) in human cells. PloS One 9:e92640. https ://doi.org/10.1371/journal.pone.0092640

Becker JS, McCarthy RL, Sidoli S, Donahue G, Kaeding KE, He Z, Lin S, Garcia BA, Zaret KS (2017) Genomic and proteomic resolution of heterochromatin and its restriction of alternate fate genes. Mol Cell 68:1023-1037.e15. https://doi.org/10.1016/j. molcel.2017.11.030

Beucher A, Birraux J, Tchouandong L, Barton O, Shibata A, Conrad S, Goodarzi AA, Krempler A, Jeggo PA, Löbrich M (2009) ATM and Artemis promote homologous recombination of radiation-induced DNA double-strand breaks in G2. EMBO J 28:3413-3427. https://doi.org/10.1038/emboj.2009.276

Boersma V, Moatti N, Segura-Bayona S, Peuscher MH, van der Torre J, Wevers BA, Orthwein A, Durocher D, Jacobs JJL (2015) MAD2L2 controls DNA repair at telomeres and DNA breaks by inhibiting $5^{\prime}$ end resection. Nature 521:537-540. https://doi. org/10.1038/nature 14216

Bonetti D, Villa M, Gobbini E, Cassani C, Tedeschi G, Longhese MP (2015) Escape of Sgs1 from Rad9 inhibition reduces the 
requirement for Sae2 and functional MRX in DNA end resection. EMBO Rep 16:351-361. https://doi.org/10.15252/embr.20143 9764

Bronshtein I, Kepten E, Kanter I, Berezin S, Lindner M, Redwood AB, Mai S, Gonzalo S, Foisner R, Shav-Tal Y, Garini Y (2015) Loss of lamin A function increases chromatin dynamics in the nuclear interior. Nat Commun 6:8044. https://doi.org/10.1038/ ncomms 9044

Brown CA, Murray AW, Verstrepen KJ (2010) Rapid expansion and functional divergence of subtelomeric gene families in yeasts. Curr Biol CB 20:895-903. https://doi.org/10.1016/j. cub.2010.04.027

Burgess SM, Kleckner N (1999) Collisions between yeast chromosomal loci in vivo are governed by three layers of organization. Genes Dev 13:1871-1883

Bystricky K, Laroche T, van Houwe G, Blaszczyk M, Gasser SM (2005) Chromosome looping in yeast. J Cell Biol 168:375-387. https://doi.org/10.1083/jcb.200409091

Cannavo E, Cejka P (2014) Sae2 promotes dsDNA endonuclease activity within Mre11-Rad50-Xrs2 to resect DNA breaks. Nature 514:122-125. https://doi.org/10.1038/nature13771

Caridi CP, D’Agostino C, Ryu T, Zapotoczny G, Delabaere L, Li X, Khodaverdian VY, Amaral N, Lin E, Rau AR, Chiolo I (2018) Nuclear F-actin and myosins drive relocalization of heterochromatic breaks. Nature 559:54-60. https://doi.org/10.1038/ s41586-018-0242-8

Caron P, Choudjaye J, Clouaire T, Bugler B, Daburon V, Aguirrebengoa M, Mangeat T, Iacovoni JS, Álvarez-Quilón A, Cortés-Ledesma F, Legube G (2015) Non-redundant functions of ATM and DNA-PKcs in response to DNA double-strand breaks. Cell Rep 13:1598-1609. https://doi.org/10.1016/j.celre p.2015.10.024

Cejka P (2015) DNA End resection: nucleases team up with the right partners to initiate homologous recombination. J Biol Chem 290:22931-22938. https://doi.org/10.1074/jbc.R115.675942

Cescutti R, Negrini S, Kohzaki M, Halazonetis TD (2010) TopBP1 functions with 53BP1 in the G1 DNA damage checkpoint. EMBO J 29:3723-3732. https://doi.org/10.1038/emboj.2010.238

Chapman JR, Barral P, Vannier J-B, Borel V, Steger M, Tomas-Loba A, Sartori AA, Adams IR, Batista FD, Boulton SJ (2013) RIF1 is essential for 53BP1-dependent nonhomologous end joining and suppression of dna double-strand break resection. Mol Cell 49:858-871. https://doi.org/10.1016/j.molcel.2013.01.002

Charpentier M, Khedher AHY, Menoret S, Brion A, Lamribet K, Dardillac E, Boix C, Perrouault L, Tesson L, Geny S, De Cian A, Itier JM, Anegon I, Lopez B, Giovannangeli C, Concordet JP (2018) CtIP fusion to Cas9 enhances transgene integration by homology-dependent repair. Nat Commun 9:1133. https://doi. org/10.1038/s41467-018-03475-7

Chaurasia P, Sen R, Pandita TK, Bhaumik SR (2012) Preferential repair of DNA double-strand break at the active gene in vivo. J Biol Chem 287:36414-36422. https://doi.org/10.1074/jbc. M112.364661

Chen X, Cui D, Papusha A, Zhang X, Chu C-D, Tang J, Chen K, Pan X, Ira G (2012) The Fun30 nucleosome remodeller promotes resection of DNA double-strand break ends. Nature 489:576-580. https://doi.org/10.1038/nature11355

Chen H, Lisby M, Symington LS (2013) RPA coordinates DNA end resection and prevents formation of DNA hairpins. Mol Cell. https://doi.org/10.1016/j.molcel.2013.04.032

Chiolo I, Minoda A, Colmenares SU, Polyzos A, Costes SV, Karpen GH (2011) Double-strand breaks in heterochromatin move outside of a dynamic HP1a domain to complete recombinational repair. Cell 144:732-744. https://doi.org/10.1016/j. cell.2011.02.012
Chubb JR, Boyle S, Perry P, Bickmore WA (2002) Chromatin motion is constrained by association with nuclear compartments in human cells. Curr Biol CB 12:439-445

Costelloe T, Louge R, Tomimatsu N, Mukherjee B, Martini E, Khadaroo B, Dubois K, Wiegant WW, Thierry A, Burma S, van Attikum H, Llorente B (2012) The yeast Fun30 and human SMARCAD1 chromatin remodellers promote DNA end resection. Nature 489:581-584. https://doi.org/10.1038/nature11353

Cremer T, Cremer M (2010) Chromosome territories. Cold Spring Harb Perspect Biol 2:a003889. https://doi.org/10.1101/cshpe rspect.a003889

Cremer M, von Hase J, Volm T, Brero A, Kreth G, Walter J, Fischer C, Solovei I, Cremer C, Cremer T (2001) Non-random radial higher-order chromatin arrangements in nuclei of diploid human cells. Chromosome Res Int J Mol Supramol Evol Asp Chromosome Biol 9:541-567

Daugaard M, Baude A, Fugger K, Povlsen LK, Beck H, Sørensen CS, Petersen NHT, Sorensen PHB, Lukas C, Bartek J, Lukas J, Rohde M, Jäättelä M (2012) LEDGF (p75) promotes DNA-end resection and homologous recombination. Nat Struct Mol Biol 19:803-810. https://doi.org/10.1038/nsmb.2314

Dibitetto D, Ferrari M, Rawal CC, Balint A, Kim T, Zhang Z, Smolka MB, Brown GW, Marini F, Pellicioli A (2016) Slx4 and Rtt107 control checkpoint signalling and DNA resection at doublestrand breaks. Nucleic Acids Res 44:669-682. https://doi. org/10.1093/nar/gkv1080

Dimitrova N, Chen Y-CM, Spector DL, de Lange T (2008) 53BP1 promotes non-homologous end joining of telomeres by increasing chromatin mobility. Nature 456:524-528. https://doi. org/10.1038/nature07433

Dion V, Gasser SM (2013) Chromatin movement in the maintenance of genome stability. Cell 152:1355-1364. https://doi.org/10.1016/j. cell.2013.02.010

Dion V, Kalck V, Horigome C, Towbin BD, Gasser SM (2012) Increased mobility of double-strand breaks requires Mec1, Rad9 and the homologous recombination machinery. Nat Cell Biol 14:502-509. https://doi.org/10.1038/ncb2465

Duan Z, Andronescu M, Schutz K, McIlwain S, Kim YJ, Lee C, Shendure J, Fields S, Blau CA, Noble WS (2010) A three-dimensional model of the yeast genome. Nature 465:363-367. https://doi. org/10.1038/nature08973

Eapen VV, Sugawara N, Tsabar M, Wu W-H, Haber JE (2012) The Saccharomyces cerevisiae chromatin remodeler Fun30 regulates DNA end resection and checkpoint deactivation. Mol Cell Biol 32:4727-4740. https://doi.org/10.1128/MCB.00566-12

Ferrari M, Dibitetto D, De Gregorio G, Eapen VV, Rawal CC, Lazzaro F, Tsabar M, Marini F, Haber JE, Pellicioli A (2015) Functional interplay between the 53BP1-ortholog $\operatorname{Rad} 9$ and the Mre11 complex regulates resection, end-tethering and repair of a double-strand break. PLoS Genet. https://doi.org/10.1371/journ al.pgen. 1004928

Filion GJ, van Bemmel JG, Braunschweig U, Talhout W, Kind J, Ward LD, Brugman W, de Castro IJ, Kerkhoven RM, Bussemaker HJ, van Steensel B (2010) Systematic protein location mapping reveals five principal chromatin types in Drosophila cells. Cell 143:212-224. https://doi.org/10.1016/j.cell.2010.09.009

Forget AL, Kowalczykowski SC (2012) Single-molecule imaging of DNA pairing by RecA reveals a three-dimensional homology search. Nature 482:423-427. https://doi.org/10.1038/nature1078 2

Fortin GS, Symington LS (2002) Mutations in yeast Rad51 that partially bypass the requirement for Rad55 and Rad57 in DNA repair by increasing the stability of Rad51-DNA complexes. EMBO J 21:3160-3170. https://doi.org/10.1093/emboj/cdf293

Gartenberg MR, Neumann FR, Laroche T, Blaszczyk M, Gasser SM (2004) Sir-mediated repression can occur independently of 
chromosomal and subnuclear contexts. Cell 119:955-967. https ://doi.org/10.1016/j.cell.2004.11.008

Giannattasio M, Lazzaro F, Plevani P, Muzi-Falconi M (2005) The DNA damage checkpoint response requires histone $\mathrm{H} 2 \mathrm{~B}$ ubiquitination by Rad6-Bre1 and H3 methylation by Dot1. J Biol Chem 280:9879-9886. https://doi.org/10.1074/jbc.M414453200

Goodarzi AA, Noon AT, Deckbar D, Ziv Y, Shiloh Y, Löbrich M, Jeggo PA (2008) ATM signaling facilitates repair of DNA double-strand breaks associated with heterochromatin. Mol Cell 31:167-177. https://doi.org/10.1016/j.molcel.2008.05.017

Granata M, Lazzaro F, Novarina D, Panigada D, Puddu F, Abreu CM, Kumar R, Grenon M, Lowndes NF, Plevani P, Muzi-Falconi M (2010) Dynamics of Rad9 chromatin binding and checkpoint function are mediated by its dimerization and are cell cycle-regulated by CDK1 activity. PLoS Genet. https://doi. org/10.1371/journal.pgen.1001047

Grenon M, Costelloe T, Jimeno S, O'Shaughnessy A, FitzGerald J, Zgheib O, Degerth L, Lowndes NF (2007) Docking onto chromatin via the Saccharomyces cerevisiae Rad9 Tudor domain. Yeast 24:105-119. https://doi.org/10.1002/yea.1441

Gu B, Posfai E, Rossant J (2017) Efficient generation of targeted large insertions in mouse embryos using 2C-HR-CRISPR. bioRxiv. https://doi.org/10.1101/204339

Hajjoul H, Mathon J, Ranchon H, Goiffon I, Mozziconacci J, Albert B, Carrivain P, Victor J-M, Gadal O, Bystricky K, Bancaud A (2013) High-throughput chromatin motion tracking in living yeast reveals the flexibility of the fiber throughout the genome. Genome Res 23:1829-1838. https://doi.org/10.1101/gr.15700 8.113

Hammet A, Magill C, Heierhorst J, Jackson SP (2007) Rad9 BRCT domain interaction with phosphorylated $\mathrm{H} 2 \mathrm{AX}$ regulates the G1 checkpoint in budding yeast. EMBO Rep 8:851-857. https ://doi.org/10.1038/sj.embor.7401036

Hauer MH, Seeber A, Singh V, Thierry R, Sack R, Amitai A, Kryzhanovska M, Eglinger J, Holcman D, Owen-Hughes T, Gasser SM (2017) Histone degradation in response to DNA damage enhances chromatin dynamics and recombination rates. Nat Struct Mol Biol 24:99-107. https://doi.org/10.1038/nsmb.3347

Hediger F, Neumann FR, Van Houwe G, Dubrana K, Gasser SM (2002) Live imaging of telomeres: yKu and Sir proteins define redundant telomere-anchoring pathways in yeast. Curr Biol CB 12:2076-2089

Heride C, Ricoul M, Kiêu K, von Hase J, Guillemot V, Cremer C, Dubrana K, Sabatier L (2010) Distance between homologous chromosomes results from chromosome positioning constraints. J Cell Sci 123:4063-4075. https://doi.org/10.1242/ jes.066498

Huertas P, Jackson SP (2009) Human CtIP mediates cell cycle control of DNA end resection and double strand break repair. J Biol Chem 284:9558-9565. https://doi.org/10.1074/jbc.M808906200

Huertas P, Cortés-Ledesma F, Sartori AA, Aguilera A, Jackson SP (2008) CDK targets Sae2 to control DNA-end resection and homologous recombination. Nature 455:689-692. https://doi. org/10.1038/nature07215

Huyen Y, Zgheib O, Ditullio RA, Gorgoulis VG, Zacharatos P, Petty TJ, Sheston EA, Mellert HS, Stavridi ES, Halazonetis TD (2004) Methylated lysine 79 of histone $\mathrm{H} 3$ targets 53BP1 to DNA double-strand breaks. Nature 432:406-411. https://doi.org/10.1038/ nature 03114

Jain S, Sugawara N, Haber JE (2016) Role of double-strand break endtethering during gene conversion in Saccharomyces cerevisiae. PLoS Genet. https://doi.org/10.1371/journal.pgen.1005976

Jakob B, Splinter J, Durante M, Taucher-Scholz G (2009) Live cell microscopy analysis of radiation-induced DNA double-strand break motion. Proc Natl Acad Sci USA 106:3172-3177. https:// doi.org/10.1073/pnas.0810987106
Janssen A, Breuer GA, Brinkman EK, van der Meulen AI, Borden SV, van Steensel B, Bindra RS, LaRocque JR, Karpen GH (2016) A single double-strand break system reveals repair dynamics and mechanisms in heterochromatin and euchromatin. Genes Dev 30:1645-1657. https://doi.org/10.1101/gad.283028.116

Javaheri A, Wysocki R, Jobin-Robitaille O, Altaf M, Côté J, Kron SJ (2006) Yeast G1 DNA damage checkpoint regulation by H2A phosphorylation is independent of chromatin remodeling. Proc Natl Acad Sci USA 103:13771-13776. https://doi.org/10.1073/ pnas.0511192103

Jia X, Weinert T, Lydall D (2004) Mec1 and Rad53 inhibit formation of single-stranded DNA at telomeres of Saccharomyces cerevisiae cdc13-1 mutants. Genetics 166:753-764

Joyce EF, Erceg J, Wu C-T (2016) Pairing and anti-pairing: a balancing act in the diploid genome. Curr Opin Genet Dev 37:119128. https://doi.org/10.1016/j.gde.2016.03.002

Kaidi A, Weinert BT, Choudhary C, Jackson SP (2010) Human SIRT6 promotes DNA end resection through CtIP deacetylation. Science 329:1348-1353. https://doi.org/10.1126/scien ce. 1192049

Kramara J, Osia B, Malkova A (2018) Break-induced replication: the where, the why, and the how. Trends Genet TIG 34:518-531. https://doi.org/10.1016/j.tig.2018.04.002

Krawczyk PM, Borovski T, Stap J, Cijsouw T, ten Cate R, Medema JP, Kanaar R, Franken N. Aten P JA (2012) Chromatin mobility is increased at sites of DNA double-strand breaks. J Cell Sci 125:2127-2133. https://doi.org/10.1242/jcs.089847

Kruhlak MJ, Celeste A, Dellaire G, Fernandez-Capetillo O, Müller WG, McNally JG, Bazett-Jones DP, Nussenzweig A (2006) Changes in chromatin structure and mobility in living cells at sites of DNA double-strand breaks. J Cell Biol 172:823-834. https://doi.org/10.1083/jcb.200510015

Lazzaro F, Sapountzi V, Granata M, Pellicioli A, Vaze M, Haber JE, Plevani P, Lydall D, Muzi-Falconi M (2008) Histone methyltransferase Dot 1 and Rad9 inhibit single-stranded DNA accumulation at DSBs and uncapped telomeres. EMBO J 27:15021512. https://doi.org/10.1038/emboj.2008.81

Lee C-S, Wang RW, Chang H-H, Capurso D, Segal MR, Haber JE (2016) Chromosome position determines the success of double-strand break repair. Proc Natl Acad Sci USA 113:E146E154. https://doi.org/10.1073/pnas. 1523660113

Leland BA, Chen AC, Zhao AY, Wharton RC, King MC (2018) Rev7 and 53BP1/Crb2 prevent RecQ helicase-dependent hyper-resection of DNA double-strand breaks. eLife. https:// doi.org/10.7554/eLife.33402

Lemaître C, Soutoglou E (2014) Double strand break (DSB) repair in heterochromatin and heterochromatin proteins in DSB repair. DNA Repair 19:163-168. https://doi.org/10.1016/j.dnare p.2014.03.015

Lemaître C, Soutoglou E (2015) DSB (Im)mobility and DNA repair compartmentalization in mammalian cells. J Mol Biol 427:652-658. https://doi.org/10.1016/j.jmb.2014.11.014

Lemaître C, Grabarz A, Tsouroula K, Andronov L, Furst A, Pankotai T, Heyer V, Rogier M, Attwood KM, Kessler P, Dellaire G, Klaholz B, Reina-San-Martin B, Soutoglou E (2014) Nuclear position dictates DNA repair pathway choice. Genes Dev 28:2450-2463. https://doi.org/10.1101/gad.248369.114

Leshets M, Ramamurthy D, Lisby M, Lehming N, Pines O (2018) Fumarase is involved in DNA double-strand break resection through a functional interaction with Sae2. Curr Genet 64:697712. https://doi.org/10.1007/s00294-017-0786-4

Li G, Reinberg D (2011) Chromatin higher-order structures and gene regulation. Curr Opin Genet Dev 21:175-186. https:// doi.org/10.1016/j.gde.2011.01.022

Li J, Coïc E, Lee K, Lee C-S, Kim J-A, Wu Q, Haber JE (2012) Regulation of budding yeast mating-type switching donor preference 
by the FHA domain of Fkh1. PLoS Genet 8:e1002630. https:// doi.org/10.1371/journal.pgen.1002630

Liu Y, Cussiol JR, Dibitetto D, Sims JR, Twayana S, Weiss RS, Freire R, Marini F, Pellicioli A, Smolka MB (2017) TOPBP1Dpb11 plays a conserved role in homologous recombination DNA repair through the coordinated recruitment of 53BP1Rad9. J Cell Biol 216:623-639. https://doi.org/10.1083/jcb.201607031

Llorente B, Smith CE, Symington LS (2008) Break-induced replication: what is it and what is it for? Cell Cycle Georget Tex 7:859-864. https://doi.org/10.4161/cc.7.7.5613

Lorenz A, Fuchs J, Bürger R, Loidl J (2003) Chromosome pairing does not contribute to nuclear architecture in vegetative yeast cells. Eukaryot Cell 2:856-866

Lottersberger F, Karssemeijer RA, Dimitrova N, de Lange T (2015) 53BP1 and the LINC complex promote microtubule-dependent DSB mobility and DNA repair. Cell 163:880-893. https://doi. org/10.1016/j.cell.2015.09.057

Lue NF, Yu EY (2017) Telomere recombination pathways: tales of several unhappy marriages. Curr Genet 63:401-409. https:// doi.org/10.1007/s00294-016-0653-8

Lundblad V, Blackburn EH (1993) An alternative pathway for yeast telomere maintenance rescues est 1 - senescence. Cell 73:347-360

Lydall D, Weinert T (1995) Yeast checkpoint genes in DNA damage processing: implications for repair and arrest. Science 270:1488-1491

Lyndaker AM, Alani E (2009) A tale of tails: insights into the coordination of $3^{\prime}$ end processing during homologous recombination. BioEssays News Rev Mol Cell Dev Biol 31:315-321. https://doi. org/10.1002/bies.200800195

Ma M, Zhuang F, Hu X, Wang B, Wen X-Z, Ji J-F, Xi JJ (2017) Efficient generation of mice carrying homozygous double-floxp alleles using the Cas9-Avidin/Biotin-donor DNA system. Cell Res 27:578-581. https://doi.org/10.1038/cr.2017.29

Marshall WF, Fung JC (2016) Modeling meiotic chromosome pairing: nuclear envelope attachment, telomere-led active random motion, and anomalous diffusion. Phys Biol 13:26003. https:// doi.org/10.1088/1478-3975/13/2/026003

McEachern MJ, Haber JE (2006) Break-induced replication and recombinational telomere elongation in yeast. Annu Rev Biochem 75:111-135. https://doi.org/10.1146/annurev.biochem.74.08280 3.133234

Mehta A, Beach A, Haber JE (2017) Homology requirements and competition between gene conversion and break-induced replication during double-strand break repair. Mol Cell 65:515-526.e3. https ://doi.org/10.1016/j.molcel.2016.12.003

Mimitou EP, Symington LS (2008) Sae2, Exo1 and Sgs1 collaborate in DNA double-strand break processing. Nature 455:770-774. https://doi.org/10.1038/nature07312

Miné-Hattab J, Rothstein R (2012) Increased chromosome mobility facilitates homology search during recombination. Nat Cell Biol 14:510-517. https://doi.org/10.1038/ncb2472

Morin I, Ngo H-P, Greenall A, Zubko MK, Morrice N, Lydall D (2008) Checkpoint-dependent phosphorylation of Exo1 modulates the DNA damage response. EMBO J 27:2400-2410. https://doi. org/10.1038/emboj.2008.171

Neumaier T, Swenson J, Pham C, Polyzos A, Lo AT, Yang P, Dyball J, Asaithamby A, Chen DJ, Bissell MJ, Thalhammer S, Costes SV (2012) Evidence for formation of DNA repair centers and doseresponse nonlinearity in human cells. Proc Natl Acad Sci USA 109:443-448. https://doi.org/10.1073/pnas.1117849108

Neumann FR, Dion V, Gehlen LR, Tsai-Pflugfelder M, Schmid R, Taddei A, Gasser SM (2012) Targeted INO80 enhances subnuclear chromatin movement and ectopic homologous recombination. Genes Dev 26:369-383. https://doi.org/10.1101/gad.176156.111
Noon AT, Shibata A, Rief N, Löbrich M, Stewart GS, Jeggo PA, Goodarzi AA (2010) 53BP1-dependent robust localized KAP-1 phosphorylation is essential for heterochromatic DNA doublestrand break repair. Nat Cell Biol 12:177-184. https://doi. org/10.1038/ncb2017

Ochs F, Somyajit K, Altmeyer M, Rask M-B, Lukas J, Lukas C (2016) 53BP1 fosters fidelity of homology-directed DNA repair. Nat Struct Mol Biol 23:714-721. https://doi.org/10.1038/nsmb.3251

Peng JC, Karpen GH (2009) Heterochromatic genome stability requires regulators of histone $\mathrm{H} 3 \mathrm{~K} 9$ methylation. PLoS Genet 5:e1000435. https://doi.org/10.1371/journal.pgen.1000435

Pfander B, Diffley JFX (2011) Dpb11 coordinates Mec1 kinase activation with cell cycle-regulated Rad9 recruitment. EMBO J 30:4897-4907. https://doi.org/10.1038/emboj.2011.345

Piazza A, Wright WD, Heyer W-D (2017) Multi-invasions are recombination byproducts that induce chromosomal rearrangements. Cell 170:760-773.e15. https://doi.org/10.1016/j.cell.2017.06.052

Politz JCR, Scalzo D, Groudine M (2013) Something silent this way forms: the functional organization of the repressive nuclear compartment. Annu Rev Cell Dev Biol 29:241-270. https://doi. org/10.1146/annurev-cellbio-101512-122317

Rao SSP, Huntley MH, Durand NC, Stamenova EK, Bochkov ID, Robinson JT, Sanborn AL, Machol I, Omer AD, Lander ES, Aiden EL (2014) A 3D map of the human genome at kilobase resolution reveals principles of chromatin looping. Cell 159:1665-1680. https://doi.org/10.1016/j.cell.2014.11.021

Robert T, Vanoli F, Chiolo I, Shubassi G, Bernstein KA, Rothstein R, Botrugno OA, Parazzoli D, Oldani A, Minucci S, Foiani M (2011) HDACs link the DNA damage response, processing of double-strand breaks and autophagy. Nature 471:74-79. https:// doi.org/10.1038/nature09803

Rong YS, Golic KG (2003) The homologous chromosome is an effective template for the repair of mitotic DNA double-strand breaks in Drosophila. Genetics 165:1831-1842

Roy KR, Smith JD, Vonesch SC, Lin G, Tu CS, Lederer AR, Chu A, Suresh S, Nguyen M, Horecka J, Tripathi A, Burnett WT, Morgan MA, Schulz J, Orsley KM, Wei W, Aiyar RS, Davis RW, Bankaitis VA, Haber JE, Salit ML, St.Onge RP, Steinmetz LM (2018) Multiplexed precision genome editing with trackable genomic barcodes in yeast. Nat Biotechnol 36:512-520. https:// doi.org/10.1038/nbt.4137

Ryu T, Spatola B, Delabaere L, Bowlin K, Hopp H, Kunitake R, Karpen GH, Chiolo I (2015) Heterochromatic breaks move to the nuclear periphery to continue recombinational repair. Nat Cell Biol 17:1401-1411. https://doi.org/10.1038/ncb3258

Savic N, Ringnalda F, Bargsten K, Li Y, Berk C, Hall J, Neri D, Jinek M, Schwank G (2017) Covalent linkage of the DNA repair template to the CRISPR/Cas9 complex enhances homology-directed repair. bioRxiv. https://doi.org/10.1101/218149

Schober H, Kalck V, Vega-Palas MA, Van Houwe G, Sage D, Unser M, Gartenberg MR, Gasser SM (2008) Controlled exchange of chromosomal arms reveals principles driving telomere interactions in yeast. Genome Res 18:261-271. https://doi.org/10.1101/ gr.6687808

Schrank BR, Aparicio T, Li Y, Chang W, Chait BT, Gundersen GG, Gottesman ME, Gautier J (2018) Nuclear ARP2/3 drives DNA break clustering for homology-directed repair. Nature 559:61-66. https://doi.org/10.1038/s41586-018-0237-5

Seeber A, Dion V, Gasser SM (2013) Checkpoint kinases and the INO80 nucleosome remodeling complex enhance global chromatin mobility in response to DNA damage. Genes Dev 27:19992008. https://doi.org/10.1101/gad.222992.113

Shimada K, Gasser SM (2017) A game of musical chairs: pro- and antiresection factors compete for TOPBP1 binding after DNA damage. J Cell Biol 216:535-537. https://doi.org/10.1083/jcb.20170 1038 
Shinohara A, Ogawa H, Ogawa T (1992) Rad51 protein involved in repair and recombination in S. cerevisiae is a RecA-like protein. Cell 69:457-470

Smith MJ, Rothstein R (2017) Poetry in motion: Increased chromosomal mobility after DNA damage. DNA Repair 56:102-108. https://doi.org/10.1016/j.dnarep.2017.06.012

Soutoglou E, Dorn JF, Sengupta K, Jasin M, Nussenzweig A, Ried T, Danuser G, Misteli T (2007) Positional stability of single doublestrand breaks in mammalian cells. Nat Cell Biol 9:675-682. https ://doi.org/10.1038/ncb1591

Spichal M, Brion A, Herbert S, Cournac A, Marbouty M, Zimmer C, Koszul R, Fabre E (2016) Evidence for a dual role of actin in regulating chromosome organization and dynamics in yeast. $\mathbf{J}$ Cell Sci 129:681-692. https://doi.org/10.1242/jcs.175745

Stark JM, Pierce AJ, Oh J, Pastink A, Jasin M (2004) Genetic steps of mammalian homologous repair with distinct mutagenic consequences. Mol Cell Biol 24:9305-9316. https://doi.org/10.1128/ MCB.24.21.9305-9316.2004

Stimpson KM, Song IY, Jauch A, Holtgreve-Grez H, Hayden KE, Bridger JM, Sullivan BA (2010) Telomere disruption results in non-random formation of de novo dicentric chromosomes involving acrocentric human chromosomes. PLoS Genet. https://doi. org/10.1371/journal.pgen.1001061

Strecker J, Gupta GD, Zhang W, Bashkurov M, Landry M-C, Pelletier L, Durocher D (2016) DNA damage signalling targets the kinetochore to promote chromatin mobility. Nat Cell Biol 18:281-290. https://doi.org/10.1038/ncb3308

Sung P (1994) Catalysis of ATP-dependent homologous DNA pairing and strand exchange by yeast RAD51 protein. Science 265:1241-1243

Symington LS (2016) Mechanism and regulation of DNA end resection in eukaryotes. Crit Rev Biochem Mol Biol 51:195-212. https:// doi.org/10.3109/10409238.2016.1172552

Symington LS, Gautier J (2011) Double-strand break end resection and repair pathway choice. Annu Rev Genet 45:247-271. https://doi. org/10.1146/annurev-genet-110410-132435

Symington LS, Rothstein R, Lisby M (2014) Mechanisms and regulation of mitotic recombination in Saccharomyces cerevisiae. Genetics 198:795-835. https://doi.org/10.1534/genet ics.114.166140

Taddei A, Schober H, Gasser SM (2010) The budding yeast nucleus. Cold Spring Harb Perspect Biol 2:a000612. https://doi. org/10.1101/cshperspect.a000612

Tang J, Cho NW, Cui G, Manion EM, Shanbhag NM, Botuyan MV, Mer G, Greenberg RA (2013) Acetylation limits 53BP1 association with damaged chromatin to promote homologous recombination. Nat Struct Mol Biol 20:317-325. https://doi.org/10.1038/ nsmb.2499

Therizols P, Duong T, Dujon B, Zimmer C, Fabre E (2010) Chromosome arm length and nuclear constraints determine the dynamic relationship of yeast subtelomeres. Proc Natl Acad Sci USA 107:2025-2030. https://doi.org/10.1073/pnas.0914187107

Toledo LI, Altmeyer M, Rask M-B, Lukas C, Larsen DH, Povlsen LK, Bekker-Jensen S, Mailand N, Bartek J, Lukas J (2013) ATR prohibits replication catastrophe by preventing global exhaustion of RPA. Cell 155:1088-1103. https://doi.org/10.1016/j. cell.2013.10.043

Tomimatsu N, Mukherjee B, Harris JL, Boffo FL, Hardebeck MC, Potts PR, Khanna KK, Burma S (2017) DNA-damage-induced degradation of EXO1 exonuclease limits DNA end resection to ensure accurate DNA repair. J Biol Chem 292:10779-10790. https://doi.org/10.1074/jbc.M116.772475

Tsouroula K, Furst A, Rogier M, Heyer V, Maglott-Roth A, Ferrand A, Reina-San-Martin B, Soutoglou E (2016) Temporal and spatial uncoupling of DNA double strand break repair pathways within mammalian heterochromatin. Mol Cell 63:293-305. https://doi. org/10.1016/j.molcel.2016.06.002

van Steensel B (2011) Chromatin: constructing the big picture. EMBO J 30:1885-1895. https://doi.org/10.1038/emboj.2011.135

van Leeuwen F, Gafken PR, Gottschling DE (2002) Dot1p modulates silencing in yeast by methylation of the nucleosome core. Cell 109:745-756. https://doi.org/10.1016/S0092-8674(02)00759-6

Vasquez PA, Bloom K (2014) Polymer models of interphase chromosomes. Nucl Austin Tex 5:376-390. https://doi.org/10.4161/ nucl. 36275

Verdaasdonk JS, Vasquez PA, Barry RM, Barry T, Goodwin S, Forest MG, Bloom K (2013) Centromere tethering confines chromosome domains. Mol Cell 52:819-831. https://doi.org/10.1016/j. molcel.2013.10.021

Villa M, Bonetti D, Carraro M, Longhese MP (2018) Rad9/53BP1 protects stalled replication forks from degradation in Mec1/ATRdefective cells. EMBO Rep 19:351-367. https://doi.org/10.15252 lembr.201744910

Wilson JH, Leung WY, Bosco G, Dieu D, Haber JE (1994) The frequency of gene targeting in yeast depends on the number of target copies. Proc Natl Acad Sci USA 91:177-181

Winey M, Bloom K (2012) Mitotic spindle form and function. Genetics 190:1197-1224. https://doi.org/10.1534/genetics.111.128710

Wright WD, Shah SS, Heyer W-D (2018) Homologous recombination and the repair of DNA double-strand breaks. J Biol Chem 293:10524-10535. https://doi.org/10.1074/jbc.TM118.000372

Wysocki R, Javaheri A, Allard S, Sha F, Côté J, Kron SJ (2005) Role of Dot1-dependent histone $\mathrm{H} 3$ methylation in $\mathrm{G} 1$ and S phase DNA damage checkpoint functions of Rad9. Mol Cell Biol 25:8430 8443. https://doi.org/10.1128/MCB.25.19.8430-8443.2005

Xu G, Chapman JR, Brandsma I, Yuan J, Mistrik M, Bouwman P, Bartkova J, Gogola E, Warmerdam D, Barazas M, Jaspers JE, Watanabe K, Pieterse M, Kersbergen A, Sol W, Celie PHN, Schouten PC, van den Broek B, Salman A, Nieuwland M, de Rink I, de Ronde J, Jalink K, Boulton SJ, Chen J, van Gent DC, Bartek J, Jonkers J, Borst P, Rottenberg S (2015) REV7 counteracts DNA double-strand break resection and affects PARP inhibition. Nature 521:541-544. https://doi.org/10.1038/nature14328

Zierhut C, Diffley JFX (2008) Break dosage, cell cycle stage and DNA replication influence DNA double strand break response. EMBO J 27:1875-1885. https://doi.org/10.1038/emboj.2008.111

Zimmer C, Fabre E (2011) Principles of chromosomal organization: lessons from yeast. J Cell Biol 192:723-733. https://doi. org/10.1083/jcb.201010058

Zimmer C, Fabre E (2018) Chromatin mobility upon DNA damage: state of the art and remaining questions. Curr Genet. https://doi. org/10.1007/s00294-018-0852-6

Zimmermann M, Lottersberger F, Buonomo SB, Sfeir A, de Lange T (2013) 53BP1 regulates DSB repair using Rif1 to control 5' end resection. Science 339:700-704. https://doi.org/10.1126/scien ce. 1231573 